\title{
O campo recente de estudos sobre os movimentos sociais no Brasil: um balanço crítico a partir dos conceitos de permeabilidade estatal e repertórios ${ }^{1}$
}

\author{
Diego Matheus de Menezes²
}

\begin{abstract}
Resumo: Este artigo consiste em um balanço crítico sobre as contribuições, avanços e limitações de dois conceitos chaves presentes nas análises sobre movimentos sociais no Brasil: a permeabilidade da esfera estatal e o conceito de repertórios. A partir da análise crítica da literatura sobre o referido campo de estudos, argumentase a pertinência e urgência de analisar como repertórios formados por práticas tão diversificadas se transformam e desafiam as barreiras impostas pelas assimetrias na permeabilidade.
\end{abstract}

Palavras-chave: Movimentos sociais; permeabilidade; repertórios.

\section{The recent field of studies on social movements in Brazil: a critical balance based on the concepts of state permeability and repertoires}

Abstract: This article consists of a critical review of the contributions, advances and limitations of two key concepts present in the analysis of social movements in Brazil:

\footnotetext{
${ }^{1}$ Este artigo se refere a discussões teóricas preliminares referentes a uma tese de doutorado em curso financiada pela Coordenação de Aperfeiçoamento de Pessoal de Nível Superior (CAPES). Recebido em 02/02/18 e aprovado em $01 / 07 / 18$.

${ }^{2}$ Doutorando em Ciências Sociais no PPGCS/UFBA. Desenvolve pesquisa sobre participação política, democracia, movimentos sociais e políticas públicas. E-mail: ego.matheus@gmail.com
} 
the permeability of the state sphere and the concept of repertoires. From the critical analysis of the literature on this field of study, it is argued the relevance and urgency of analyzing how repertoires formed by such diverse practices transform and challenge the barriers imposed by asymmetries in permeability.

Keywords: Social movements; permeability; repertoires.

\section{El campo reciente de estudios sobre los movimientos sociales en Brasil: un balance crítico a partir de los conceptos de permeabilidad estatal y repertorios}

Resumen: Este artículo consiste en un balance crítico sobre las contribuciones, avances y limitaciones de dos conceptos claves presentes en los análisis sobre movimientos sociales en Brasil: la permeabilidad de la esfera estatal y el concepto de repertorios. A partir del análisis crítico de la literatura sobre el referido campo de estudios, se argumenta la pertinencia y urgencia de analizar cómo repertorios formados por prácticas tan diversificadas se transforman y desafían las barreras impuestas por las asimetrías en la permeabilidad.

Palabras clave: Movimientos sociales; permeabilidad; repertorios.

\section{Introdução}

Nas últimas décadas, um vigoroso campo de estudos sobre os movimentos sociais se consolidou nas ciências sociais estimulando uma investigação detalhada sobre o objeto em questão. Decerto, a novidade do surgimento desse fenômeno e a velocidade da ampliação de sua atuação contribuíram para a referida ebulição de estudos. Não obstante, em diálogo crítico com as contribuições americanas e europeias, no Brasil consolida-se, a partir dos anos 2000, um profícuo enfoque analítico sobre a temática. Desse modo, o diálogo entre estudos diversos possibilitou a conformação de abordagens comuns, com contribuições bem delineadas. Algumas perspectivas, escolhas metodológicas e conceitos têm sido compartilhados, de forma que é possível afirmar a existência de um arcabouço mais ou menos comum sobre movimentos sociais na sociologia política e ciência política brasileira. 
Em suma, esse artigo pretende se debruçar e traçar algumas reflexões críticas sobre dois conceitos amplamente utilizados por esse campo analítico: o conceito de permeabilidade estatal e conceito de repertórios. Na primeira seção, abordaremos a ideia da permeabilidade estatal, presente sobretudo na concepção de que o Estado é permeável à atuação dos movimentos sociais. Desse modo, traçaremos as principais contribuições relacionadas ao manejo desse conceito pela literatura que versa sobre a interação dos movimentos sociais com o Estado. Por fim, será discutido sobre algumas lacunas e problemáticas relacionados com um enfoque na permeabilidade que não leve em consideração as assimetrias na inserção de atores tão diversos na esfera estatal.

Na segunda seção, será discutido o uso do conceito de repertórios bem como as adaptações e contribuições relacionadas com seu emprego. Além disso, pontuaremos sobre algumas possíveis limitações recorrentes em sua utilização.

\section{Permeabilidade estatal e a interação entre movimentos sociais e Estado}

A interação entre movimentos sociais e o Estado como perspectiva de análise têm se consolidado como importante campo de pesquisa das ciências sociais, sobretudo da ciência política brasileira. Os estudos em questão se baseiam na ideia de que as conexões entre os movimentos sociais e o Estado não só são um objeto passível de serem observadas, como são essenciais para compreender a atuação dos movimentos sociais no Brasil (DAGNINO, OLVERA e PANFICHI 2006; TATAGIBA, 2011; CARLOS, 2011; ABERS e VON BULLOW 2011; ABERS, SERAFIM e TATAGIBA 2014; DOWBOR, 2012). Assim, esta agenda de pesquisa surge no Brasil a partir do diálogo e da crítica a um diversificado corpo de estudos que se debruçou em investigar os movimentos sociais na Europa e nos Estados Unidos a partir das relações conflituosas com o Estado (MELUCCI, 1985; TARROW 2009; DIANI 1992; DELLA PORTA e DIANI, 2006; McADAM 2006). Além disso, marca o rompimento com um primeiro ciclo de análises sobre movimentos sociais no Brasil. Segundo Thiago Trindade (2017), 
até a década de 90 preponderava no campo estudos de caráter prescritivo onde a relação entre movimentos sociais e Estado era definida a partir do confronto. A atuação em espaços institucionais era investigada sob a ótica da institucionalização e burocratização, não havendo espaço para análises mais aprofundadas sobre a interação desses atores.

Entretanto, os estudos recentes que buscam analisar a interação entre os movimentos sociais e o Estado têm indicado que a tradição da relação socioestatal no Brasil torna necessária a ampliação da análise no intuito de incluir também as relações não conflituosas, como por exemplo, as interações que ocorrem nos espaços institucionais. (CARLOS, 2011; ABERS e VON BULLOW 2011). A principal argumentação para esse raciocínio é que principalmente a partir da redemocratização do Brasil, os movimentos sociais despontaram como importantes atores políticos, atuando em diversas frentes, inclusive participando de espaços institucionalizados de diálogo (AVRITZER, 2012). Euzenéia Carlos, ilustra bem a crítica ao ciclo de estudos anterior:

No entanto, o pressuposto desses teóricos de correlação entre complexificação organizacional e desmobilização do movimento, desconsidera os incentivos gerados à participação pelo desenho inovativo das instituições participativas. E, por outro lado, a compreensão dos efeitos do engajamento institucional sobre os movimentos, restrita ao seu núcleo organizacional, desprivilegia outras dimensões da ação coletiva como a relacional e a cultural - imprescindíveis à compreensão dos PACs [padrões de ação coletiva] em contextos de interação com a institucionalidade política. (CARLOS, 2011, pg.316-317).

A superação da dicotomia cooptação / cooperação possibilitou um giro analítico nas abordagens sobre a relação dos movimentos sociais e Estado na perspectiva em que possibilitava investigar com maior acuidade a interação entre atores políticos dentro e fora das fronteiras do Estado, destrinchando as dinâmicas das novas instituições participativas consolidadas a partir da 
redemocratização. A inserção da sociedade civil e dos movimentos sociais em ambientes institucionais passa a ser relevante para uma abordagem relacional que pensa a política a partir da mútua influência entre atores diversos. Desse modo, a perspectiva prescritiva perdeu espaço para um enfoque relacional na medida em que a própria realidade empírica apontava para as limitações das abordagem do primeiro ciclo de estudos sobre movimentos sociais e sociedade civil no Brasil. Esse fenômeno possibilitou um relevante amadurecimento dessa agenda de pesquisa, propiciando um desenvolvimento profícuo de métodos, estratégias e técnicas que munissem os pesquisadores de instrumentos para investigar a dinâmica da interação entre movimentos sociais e Estado. Como bem pontua Lavalle:

Essa mudança tem desdobramentos analíticos relevantes em pelo menos três planos: as análises sociológicas da ação social, tradicionalmente focadas em atores e/ou sujeitos coletivos, agora esquadrinham as dinâmicas de espaços e ambientes institucionais (orçamento participativo, conselhos), assim como seus efeitos sobre os atores e interesses da sociedade civil neles representados; a tradicional dicotomia da filosofia política "sociedade civil/Estado", via de regra interpretada nas análises sociais em chave de antagonismo, recebe hoje tratamento em termos de sinergia, complementaridade e conflituosidade animadas pela lógica política do governo da ocasião, e não pelas características estruturais do Estado; por fim, o caráter enfaticamente normativo da literatura dos anos 1990, engajada no esclarecimento da missão transformadora da sociedade civil, cede passo a indagações mais preocupadas com a compreensão empírica de processos em curso, notadamente os alcances, entraves e limitações das novas formas de interação entre a sociedade civil e o Estado. (LAVALLE, 2003, pg. 109). 
A discussão sobre os efeitos da interaçãoé vasta e diversificada na literatura sobre movimentos sociais. Meyer e Tarrow (1998) indicam que a aproximação dos movimentos sociais ao Estado pode ter como resultado a cooptação, a perda de autonomia e o enfraquecimento dos movimentos. Segundo Giugni e Passy (1998), entretanto, a aproximação dos movimentos com as instâncias do Estado não tem necessariamente como resultado a burocratização e descaracterização dos movimentos. Os autores desenvolveram o conceito de cooperação conflitual, apontando para a possibilidade de que mesmo nas relações baseadas na cooperação nos espaços institucionais o conflito está presente, possibilitando, inclusive, certa autonomia do movimento. Nessa perspectiva cooperação e conflito não são antagônicas, sendo combinadas nos diversos espaços de atuação.

Tatagiba (2011), pontua que uma série de fatores pesam nas escolhas das estratégias, como a estrutura das organizações, as dinâmicas conjunturais e a posição relacional dos atores. O contexto político se apresenta como um fator importante criando ou diminuindo a eficácia de determinadas estratégias. Tendo isso em vista, o diálogo com o conceito de estrutura de oportunidades políticas de Tarrow apresenta-se profícuo. Segundo o autor, estrutura de oportunidades políticas são "dimensões consistentes - mas não necessariamente formais, permanentes ou racionais - da luta política que encorajam as pessoas a se engajar no confronto político" (TARROW, 2009, pg. 38). Nessa perspectiva, as organizações dos movimentos sociais atuam em um contexto onde certas estratégias são estimuladas e outras desestimuladas. Os movimentos e suas organizações, por sua vez, tentam construir, a partir das oportunidades, uma conjuntura favorável. Estamos falando, portanto de um processo dinâmico.

Por outro lado, Gerardo Munck (1997) ao discutir a ideia de estratégia política, aponta para os possíveis riscos na escolha das estratégias. O autor apresenta que "o desafio crucial do problema da estratégia política pode ser enunciado diretamente em termos da influência recíproca entre as dimensões da identidade e da estratégia" (MUNCK, 1997). Ou seja, um movimento social ao 
tentar articular e conquistar suas pautas não têm alternativa ao não ser adotar a ação estratégica, criando uma tensão entre identidade e estratégia que "possibilita ou prejudica o pleno desenvolvimento do movimento, dependendo da maneira como é tratado". (MUNCK, 1997).

Dentre as principais ações e estratégias relacionadas com a cooperação entre movimentos sociais e Estado, destacam-se a atuação em instituições participativas e o ativismo institucional. Este último possibilita um intenso trânsito de militantes em esferas estatais, conectando os movimentos sociais com partidos políticos e ambientes institucionais. De acordo com Silva e Oliveira:

O trânsito institucional se caracteriza pelo deslocamento contínuo de militantes sociaispartidários por diferentes espaços de atuação (organizações sociais, partidos, fóruns institucionais e posições governamentais), o qual é, em grande medida, possibilitado pela interpenetração partidomovimento. (...) Essa ênfase na centralidade do trânsito institucional como mecanismo de permeabilidade entre movimentos sociais e Estado, conformando um quadro de expressiva intersecção Estado-Movimentos, parece ser um argumento analiticamente fértil para romper com abordagens simplistas que ignoram as complexas relações estabelecidas entre organizações sociais, partidos e Estado, as quais se produzem no Brasil, em grande parte, através do deslocamento e compartilhamento de seus integrantes (SILVA e OLIVEIRA, 2011, pg. 98 - pg. 99).

De certo modo, o elemento-chave da abordagem apresentada está na ideia de um Estado permeável à sociedade civil, ou seja, um Estado como espaço heterogêneo, composto por um conjunto de instituições e de relações sociais, onde diversos atores disputam e articulam projetos políticos que perpassam tanto o Estado quanto a sociedade civil (DAGNINO, OLVERA e PANFICHI, 2006).

Contudo, apontar que existe algo de permeável no Estado, se configura somente como uma abordagem parcial. 
Se cruzarmos os resultados obtidos sobre a permeabilidade estatal entre estudos sobre movimentos sociais e estudos sobre redes empresariais (MARQUES,1999; 1998) nos deparamos com relevantes disparidades relacionadas à capacidade desses atores em se inserirem em redes não periféricas do tecido estatal. Conforme Marques, a relação entre redes empresariais e Estado ocorre com intensidade, se configurando como elemento relevante para compreender o processo de formulação de políticas públicas. $\mathrm{O}$ autor desenvolve um conceito de permeabilidade em diálogo com a noção de um Estado composto por um tecido relacional perpassado por conexões entre o setor público e privado. Nas palavras do autor:

Sugeri, em contrapartida, o conceito de tecido relacional do Estado e de sua permeabilidade. [...] $\mathrm{O}$ tecido relacional expressa os padrões de conexão entre atores estatais e não estatais em redes baseadas em relações formais e informais de diversos tipos. Essas redes estruturam o Estado internamente e o conectam com o ambiente político mais amplo que o cerca. A permeabilidade, por sua vez, diz respeito especificamente às conexões entre o setor privado e o Estado no interior daquele tecido. [...] A partir dessa dimensão é possível compreender como o Estado pode ser ao mesmo tempo mais central na produção de políticas, menos insulado e mais interpenetrado por agentes privados, do que considerado pela literatura internacional. (MARQUES, 2017, pg.11 - pg. 12)

A partir dessa abordagem, Marques tem apresentado um conjunto de estudos que investigam as conexões entre empresas privadas e poder público apontando para a existência de complexas redes que influenciam nas escolhas públicas a partir, dentre outras variáveis, do poder posicional, ou seja, do poder relacionado à posição que os atores ocupam na rede (MARQUES, 1998; 1999; 2003; 2016). Um maior número de conexões na rede ou fácil acesso a atores centrais, por exemplo, tem se demonstrado relevante para 
atores privados no acesso a licitações e para influenciarem políticas públicas.

Além disso, Marques tem aprofundado a discussão sobre a capacidade dos capitais impactarem nas escolhas públicas. Em pesquisas recentes aponta os capitais urbanos como um "ator potencialmente muito importante para as políticas urbanas" (MARQUES, 2016, pg. 16), com a capacidade de manejar recursos de poder e se conectar estrategicamente com diversos atores no intuito de influenciar na produção de políticas relacionadas aos seus interesses (MARQUES, 2016).

Decerto, na dinâmica da interação entre capitais e Estado, práticas não acessíveis aos movimentos sociais são manejadas. A capacidade de executar e gerir obras públicas, por exemplo, pode possibilitar uma potencial inserção diferente na malha estatal do que a comumente ocorrida a partir dos repertórios acessados pelos movimentos sociais. Nesse sentido, é importante ressaltar que a produção de políticas públicas não ocorre somente a partir da interação entre os movimentos sociais e o Estado, pois, como já abordado, outros atores também se articulam constantemente. Ao minimizar que outros atores com interesses diversos ao de movimentos sociais e com maior capacidade de influenciar na dinâmica relacional, também compõe o tecido estatal, uma parte da literatura ignora que estamos tratando de um processo perpassado por conflitos. Argumento, portanto, que essa abordagem é incompleta enquanto não tratar das assimetrias da permeabilidade no interior do Estado.

Sobre as desigualdades de poder no acesso à esfera política, Luís Felipe Miguel discorre sobre as limitações da incorporação de grupos marginais. As assimetrias no manejo de recursos diversos não são contornadas apenas com a inserção dos atores na esfera política, na medida em que a desigualdade no acesso ao poder cria barreiras para a efetividade da ação política. Nesse sentido:

A incorporação à esfera política de grupos antes impedidos de chegar a ela é importante e necessária, mas não significa, em nenhuma medida, a superação 
do problema da desigualdade de poder. As desigualdades marcam a presença desses grupos e agem de forma permanente no sentido de orientar e limitar sua ação. Eles possuem menor controle dos recursos materiais, a começar pelo tempo livre, que são a base da ação política. São menos hábeis na produção do discurso adequado, até porque em geral são menos treinados para o debate, muitas vezes ocupando posições profissionais subalternas em que não participam da tomada das decisões. E têm maior dificuldade em fazer com que seus interesses transitem como interesses universais, pois mudanças na ordem social geram beneficiados e prejudicados, ao passo que a manutenção do status quo pode se apresentar como neutra. (MIGUEL, 2014, pg. 159).

Em consonância a essa discussão, Thiago Trindade e Caio Bugiato tem questionado que apesar das pesquisas demonstrarem que os movimentos sociais não podem ser considerados necessariamente "outsiders" na relação com o Estado, isso não os torna automaticamente "insiders" (TRINDADE e BUGIATO, 2017). Resgatando o conceito seletividade das instituições políticas de Claus Offe, no qual o sistema classista de seletividade das instituições políticas garantiria a exclusão de interesses antagônicos aos da burguesia, os autores argumentam que estar dentro do Estado não significa ter poder estatal (TRINDADE e BUGIATO, 2017, pg. 17)

Conforme Poulantzas (2000), apesar das classes dominadas terem acesso ao Estado elas se mantêm como classes dominadas, ou seja, com capacidade limitada para definir os rumos institucionais. Não obstante, o autor pondera que não ocupar espaços institucionais pode ter efeitos nocivos no sentido em que pode possibilitar o livre avanço para o estatismo. $\mathrm{O}$ autor exemplifica bem o dilema entre a necessidade de inserção em redes estatais e seus possíveis efeitos negativos:

É sabido igualmente que as massas populares devem, paralelamente a sua eventual presença no espaço 
físico dos aparelhos de Estado, manter e desenvolver permanentemente focos e redes a distância desses aparelhos: movimentos de democracia diretamente na base e redes de autogestão. Mas estes não se situam, por mais que visem aos objetivos políticos, nem fora do Estado nem, de qualquer maneira, fora do poder, conforme as ilusões simplistas de uma pureza antiinstitucional. E ainda: colocar-se a qualquer preço fora do Estado quando se pensa em situarse por isso fora do poder (o que é então impossível) pode ser muitas vezes exatamente o melhor meio de deixar o campo livre para o estatismo, em suma, recuar nesse terreno estratégico diante do adversário. (POULANZAS, 2000, pg.156).

Combinando essa perspectiva com a analogia do "tecido estatal" traçada por Eduardo Marques, seria pertinente pensar o Estado como um tecido formado por diversas camadas. Nesse sentido, alguns atores teriam acesso às camadas periféricas enquanto outros acesso facilitado em camadas mais centrais. Propomos, portanto que pensar a ideia de uma "permeabilidade assimétrica" poderia contribuir para compreender como os mecanismos relacionados à desigualdade social e política operam no interior do Estado e sobretudo, verificar seus efeitos nos movimentos sociais.

Algumas pesquisas que temos realizado têm revelado resultados interessantes que se relacionam com a discussão proposta. Em estudo sobre a participação dos movimentos sociais no processo de formulação da Política Estadual de Resíduos Sólidos a partir da atuação do Conselho Estadual das Cidades da Bahia (ConCidades/Ba) temos indicado que o conselho funcionou como "janela de oportunidade para a inserção de pautas no processo de formulação de políticas públicas, sobretudo, a partir da dinâmica incremental ocorrida na adaptação de políticas nacionais em políticas estaduais ou municipais" (MENEZES, 2018). Essa dinâmica incremental, ou seja, a mudança política a partir de pequenos passos a partir da comparação sucessiva de pontos 
de políticas anteriores, executadas pela burocracia (LINDBLOM, 2009), propiciado pela adaptação da política federal para o contexto local, viabilizou uma inserção estratégica de pautas dos movimentos sociais, dotando-a de certa permeabilidade.

Nessa mesma perspectiva, temos desenvolvido um estudo em curso sobre a trajetória da interação do movimento de moradia com o Estado na Bahia que tem obtido resultados preliminares semelhantes ao da investigação citada. Os dados sugerem que o movimento de moradia, a partir de décadas pressão e diálogo, tem atuado em uma dinâmica incremental, conseguindo conquistas a partir das brechas possibilitadas por uma certa permeabilidade estatal.

Contudo, quando cruzamos esses dados com as pesquisas sobre a atuação dos capitais urbanos em políticas públicas de habitação, sobretudo no que se refere ao Minha Casa Minha Vida (MARQUES e RODRIGUES, 2013), temos nos deparado com uma capacidade muito além da incremental, onde grandes mudanças ocorrem em um ritmo muito mais acelerado. Essa assimetria no impacto em políticas públicas tem nos indicado, em caráter preliminar, que a análise da considerável variação no ritmo de influência nas escolhas públicas é um caminho pertinente para compreender as estratégias e possibilidades dos diversos atores. Nesse sentido, reforçamos que investigar a "permeabilidade assimétrica" do Estado aparece como um desafio central para compreender como atores que mobilizam recursos tão diversificados e acessam os espaços institucionais de forma desigual, se relacionam com o Estado e entre si.

\section{O conceito de repertórios no campo de estudos sobre os movimentos sociais no Brasil}

A segunda problemática se refere à utilização recorrente do conceito de repertórios. Esse conceito foi estabelecido por Tilly e é definido como "um conjunto limitado de rotinas que são aprendidas, compartilhadas e executadas através de um processo relativamente deliberado de escolha" (TILLY, 2005, pg 
41-pg 42). São construções culturais aprendidas a partir da luta política entre opositores e autoridades, onde as pessoas, limitadas pelas opções disponíveis de interação, tentam novas táticas vantajosas, na margem de práticas bem estabelecidas (TARROW, 1994). Aprimorado ao longo das décadas a partir de um intenso diálogo dentro do campo de estudos sobre movimentos sociais, foi reajustado por Charles Tilly na década de 90, em resposta a críticas de abordagens culturalistas (ALONSO, 2012). Inicialmente, cunhado como "repertórios de ação coletiva", se referia às práticas e forma de luta dos movimentos sociais. Contudo, ao reformulá-lo como "repertório de confronto", o autor desloca o conceito para a estrutura de confronto. Segundo Alonso:

Tilly responderia em sequência de três artigos, nos quais o que era "repertório de ação coletiva" ressurge como "repertório de confronto". Esta adjetivação responde à crítica de que o conceito trataria de dinâmicas culturais, sem se fazer acompanhar de uma teoria da cultura. A especificação "de confronto" estreita o terreno, Tilly, assim, finca pé na sociologia política e dribla controvérsias da sociologia da cultura. (...) A ambiguidade anterior, entre repertório de ator e de época, se esclarece: um repertório não é peculiar a dado grupo, mas a certa estrutura de conflito. É sempre compartilhado. (ALONSO, 2012, pg. $24-$ pg. 25)

Nesse sentido, Tilly (2005) argumenta que a ação em uma luta política ocorre a partir de rotinas aprendidas ao longo do tempo em um contexto de interação. Os atores utilizam determinada rotina (protestos, ocupações, greves, etc) porque sabem como praticá-las, estimulando reações das autoridades que buscam neutralizá-las. Da mesma forma, os insurgentes buscam reagir às respostas das autoridades, aprimorando ou criando novas rotinas. Assim, em uma dinâmica relacional, o repertório é lentamente renovado em um processo contínuo.

Segundo o autor, movimentos sociais distinguem-se de outras formas de ação coletiva pela combinação dos repertórios com 
demonstrações de valores, unidades, números e comprometimento (VUNC). Assim, adéquam distintas expressões de identidade com as práticas de confronto aprendidas em uma estrutura de conflito.

No que diz respeito aos repertórios, versões de associações de finalidade específica, reuniões públicas, marchas e outras formas de ação política existiram isoladamente muito antes de sua combinação no interior de movimentos sociais. (...) Demonstrações de VUNC ocorreram por longo tempo em martírios religiosos, sacrifícios cívicos, e resistência à conquista, mas somente a sua regularização e integração com o repertório padrão distinguiu as demonstrações dos movimentos de suas predecessoras. Nenhum elemento singular, mas a combinação do repertório com as demonstrações de VUNC no interior das campanhas, criou a característica distintiva do movimento social. (TILLY, 2010, pg. 138)

Ao longo da última década, o conceito de repertório tem sido amplamente empregado nas análises sobre movimentos sociais no Brasil. Sobretudo na sociologia política e na ciência política, um acentuado esforço no mapeamento de rotinas tem possibilitado uma maior compreensão sobre a ação de diversos atores políticos. Assim, inúmeras práticas de luta como protestos, greves, ocupações, entre outros, têm sido estudadas, assegurando a construção de um vasto número de dados.

Avritzer, por exemplo, ao analisar a atuação dos movimentos sociais e da sociedade civil no Brasil afirma que na redemocratização inúmeros movimentos sociais se aproximaram do Estado no intuito de ampliar sua incidência em políticas públicas (AVRITZER, 2012). Serafim (2013), por sua vez, ao analisar a trajetória da relação do Fórum Nacional pela Reforma Urbana (FNRU) afirma que a luta pela reforma urbana se deu também a partir de um forte lobby no legislativo por representantes do FNRU e da atuação institucional de inúmeros membros desse movimento que ocupavam espaços na estrutura estatal. 
Essas investigações têm estudado a diversidade de estratégias do movimento e seus repertórios de interação com o Estado (ABERS, SERAFIM e TATAGIBA, 2014) como a participação em espaços institucionais, ocupações de prédios e terrenos públicos, mutirões autogestionários, etc (TATAGIBA, PATERNIANI e TRINDADE, 2012). Os resultados desses estudos têm indicado para um contexto onde as estratégias de ação são construídas a partir do jogo relacional entre os movimentos sociais e as instâncias estatais (TATAGIBA, 2011). As escolhas das organizações do movimento, como por exemplo, de participar de conselhos gestores, geram ganhos e desafios (TATAGIBA e BLIKSTAD, 2011), onde a relação entre movimento e instituições políticas está permeada por uma tensão entre autonomia e eficácia política (TATAGIBA, 2009).

Ao analisar a especificidade da interação dos movimentos sociais com o Estado no Brasil, Abers, Serafim e Tatagiba, a partir do conceito de Tilly de repertórios, desenvolveram o conceito de repertórios de interação, onde além do enfoque no confronto, as práticas de interação por dentro do Estado são investigadas. Assim, Abers, Serafim e Tatagiba (2014) apresentam quatro tipos recorrentes de rotinas para a interação: participação institucional, protesto, política da proximidade e ocupação de cargos.

O repertório da participação institucional, por sua vez, possibilita o diálogo com outro campo teórico: o das instituições participativas. De uma maneira geral, diversos estudos abordam o tema das instituições participativas no Brasil, bem como seus impactos na democracia brasileira (ALMEIDA e TATAGIBA, 2012; AVRITZER, 2008, TATAGIBA 2011). A institucionalização da participação a partir da construção de diversos arranjos que possibilitam articular a estrutura governamental com a sociedade civil, inseriu atores sociais em instâncias de controle de políticas públicas, aproximando-os nas instâncias institucionais dos atores estatais. Segundo Luchmann:

(...) associações e movimentos sociais estão ampliando os seus repertórios de atuação e assumindo papéis de representação nos espaços institucionais que 
foram criados em função das reivindicações e mobilizações sociais. Preenchendo um quadro mais amplo de espaços participativos e representativos, a representação conselhista constitui-se como mais um tipo de representação alternativa ao modelo eleitoral. (...) Além da atuação em Conselhos, cuja agenda já é suficiente para consumir boa quantidade de tempo e energia participativa, há um conjunto muito mais vasto de atividades - institucionais e não institucionais - a cumprir, como audiências públicas, conferências, fóruns, assembleias, encontros, manifestações, conformando um complexo participativo que superpõe, fragmenta, e sobrecarrega a atuação dos sujeitos sociais. (LUCHMANN, 2011, pg.169 - pg.170).

Na última década, no Brasil, houve um crescimento no enfoque da análise de rotinas ditas "cooperativas". A rotina da participação institucional, sobretudo, foi extensamente estudada, contribuindo para uma maior compreensão dos processos referentes à atuação dos movimentos sociais em instituições participativas. Além disso, a nova conjuntura política e as manifestações de Junho de 2013 estimularam uma retomada nos estudos sobre rotinas disruptivas, como as ocupações, protestos, etc. Contudo, ainda é escasso na literatura o esforço de compreender como as diversas rotinas interagem entre si. $\mathrm{Ou}$ seja, por exemplo: quais seriam os impactos da participação dos movimentos sociais em instituições participativas na dinâmica dos protestos organizados por estes? Ou como se daria as conexões entre política de proximidade e ocupação de cargos?

Apesar do escasso aprofundamento sobre o diálogo entre as diversas práticas de interação, na própria literatura, evidenciase alguns indícios que reforçam a concepção de que as rotinas se influenciam mutuamente. Como exemplo, alguns resultados de uma pesquisa de Tatagiba e Teixeira sobre o movimento de moradia de São Paulo: 
O contexto dos anos de 1990 foi particularmente duro para a ação do movimento, limitando em muito o avanço das suas pautas. $\mathrm{O}$ vazio deixado pelo $\mathrm{BNH}$ não foi preenchido e não houve da parte do governo federal estratégia consistente para enfrentamento do deficit habitacional na faixa de 0 a 3 salários mínimos. A ausência de política articulada e coerente entre os níveis da federação levou a UMM [União dos Movimentos de Moradia] a atuar nas brechas, buscando garantir recursos para os programas autogestionários, a partir da combinação entre pressão e negociação principalmente no plano estadual, nos governos Fleury e Covas e, depois no plano municipal, com a eleição de Marta Suplicy, do Partido dos Trabalhadores, em 2001. (TATAGIBA e TEIXEIRA, 2016, pg. 95)

Nessa mesma perspectiva, vislumbra-se no texto de Abers, Serafim e Tatagiba que as novas estratégias cooperativas têm sido combinadas e conformadas com as antigas e disruptivas. Apesar das conexões entre as diversas rotinas não ser o enfoque da análise das autoras, quando discorrem sobre a política urbana, por exemplo, apresentam um contexto onde diversas práticas convivem e combinam para conformar as possibilidades de atuação do movimento. Segundo as autoras, o lobby parlamentar e a participação institucional foram combinadas com protestos, ocupações e marchas a partir da interação entre movimentos sociais e atores estatais. (ABERS, SERAFIM e TATAGIBA, 2014).

Em pesquisas recentes, temos feito algumas descobertas que corroboram com o abordado pelas autoras citadas. Ao estudar a atuação dos movimentos sociais no Conselho Estadual das Cidades da Bahia (ConCidades/BA) encontramos resultados que apontam para a mútua interação entre política de proximidade e a participação institucional em conselhos gestores. A constante interação entre as duas rotinas possibilitou a obtenção de informações estratégicas por parte dos conselheiros representantes dos movimentos sociais, equilibrando a disparidade inicial de informações em relação aos representantes do pode público. Além disso, a atuação no conselho gestor resultou na criação de 
laços com atores de outras esferas estatais, facilitando a política de proximidade em outros espaços do tecido estatal. Como bem aponta o seguinte trecho:

Sobre a política de proximidade algumas considerações tornam-se importantes em relação ao caso estudado. A partir das entrevistas com os gestores e com lideranças do movimento, essa rotina aparecia mais como um mecanismo para as organizações obterem informações estratégicas do que como um instrumento utilizado para conquistar pleitos. O conselho e as mesas de negociação eram os principais espaços de negociação, enquanto a política de proximidade possibilitava que os movimentos obtivessem informaçoes antes da divulgação oficial. Esse é um ponto importante, pois demonstra que as rotinas se inter-relacionam. Com a criação do ConCidades/BA um dos problemas iniciais era a disparidade entre os conselheiros representantes dos movimentos sociais e os representantes do Estado em relação a facilidade em obter informações. Nesse sentido, a política de proximidade possibilitou um maior equilíbrio, tendo em vista que lideranças, utilizando o trânsito nas diversas organizações estatais (SEDUR, CAIXA, CONDER, etc...) obtiveram informações que não seriam possíveis nos espaços formais. Em contrapartida, o próprio conselho, ao se consolidar, começou a ser um espaço importante para o fortalecimento da capacidade dos movimentos em relação a política de proximidade. As organizações do movimento de moradia, ao utilizar o conselho como espaço para articular o acesso do movimento a lideranças estatais, possibilitaram que novas relações entre lideranças e atores estatais fossem construídas. (MENEZES, 2015, pg. 98)

As conexões entre as rotinas que conformam o repertório também têm se demonstrado relevantes no estudo ainda em curso sobre a interação do movimento de moradia com o Estado na Bahia na última década. Ainda em caráter preliminar, temos investigado 
as conexões entre os protestos do movimento de moradia e a atuação em conselhos gestores. As entrevistas e análises das atas têm indicado que ao longo da última década, inúmeros protestos têm ocorrido como demonstração de força quando pautas relevantes irão ser discutidas no conselho. A utilização das duas rotinas tem acontecido a partir de sua inter-relação, ampliando a capacidade de negociação do movimento no conselho e alterando a dinâmica dos protestos realizados.

Argumentamos, portanto, que o repertório não é a soma das rotinas. Ou seja, a interação e conexão entre diferentes rotinas constrói um repertório único que não pode ser confundido com a mera agregação das mesmas. Isso ocorre, pois, não somente as práticas de luta são aprendidas ao longo do tempo e limitadas pela estrutura de conflito, como as próprias possibilidades de conexões e combinações entre elas ocorre nessa dinâmica relacional, processual e conflitiva. Nesse sentido, tornam-se necessário estudos mais aprofundados que possibilitem discutir como práticas cooperativas e disruptivas se conectam e se transformam ao longo de um determinado período. A diversidade de práticas, de certa maneira, é vital para o movimento social sobreviver em um contexto de assimetrias e intensa desigualdade. A própria heterogeneidade e capacidade de inovação de um movimento pode ser recurso essencial para rápida adaptação em conjunturas dinâmicas e em contextos quase sempre desfavoráveis.

\section{Conclusão}

Como discorrido, a análise sobre os repertórios relacionados com a interação entre movimentos sociais e Estado, bem como a concepção de uma permeabilidade estatal são pertinentes para compreender as contribuições, especificidades e dilemas de um corpo determinante nos estudos recentes sobre movimentos sociais no Brasil. Decerto, o enfoque na dinâmica relacional onde diversos atores se influenciam em um "continuum", a partir de um intenso trânsito dentro e fora das fronteiras institucionais, possibilitou novas perspectivas para o campo, construindo um aporte comum 
e compartilhado que aprofunda as noções sobre a atuação dos movimentos sociais.

Entretanto, a insuficiência de pesquisas sobre os efeitos das assimetrias na inserção dos movimentos sociais nas esferas estatais e da influência mútua entre as diversas rotinas interativas, apresenta-se como obstáculo a ser superado para análises que levem em conta a grande diversidade de conexões entre as práticas dos mais variados atores políticos.

Ressalto, todavia, que tanto o conceito da permeabilidade quanto o dos repertórios são essenciais para a compreensão da dinâmica entre movimentos sociais e Estado. O intuito desse artigo foi apontar algumas possíveis abordagens onde a utilização desses conceitos possa contribuir para uma análise mais adequada. Como desafio, analisar como repertórios formado por práticas tão diversificadas se transformam e desafiam as barreiras impostas pelas assimetrias na permeabilidade desponta como um campo pertinente para o desenvolvimento do campo.

\section{Referências}

ABERS, R; VON BÜLOW, M. Movimentos sociais na teoria e na prática: como estudar o ativismo através da fronteira entre Estado e sociedade? Sociologias, v. 13, n. 28, p. 52-84, 2011.

ABERS, R.; SERAFIM, L.; TATAGIBA, L. Repertórios de interação estado-sociedade em um estado heterogêneo: a experiência na Era Lula. Dados [online], v. 57, n. 2, p. 325-357, 2014.

ALMEIDA, C.; TATAGIBA, L. Os conselhos gestores sob o crivo da política: balanços e perspectivas. Serviço Social e Sociedade, n. 109, p. 68-92. 2012.

ALONSO,A. Repertório, segundo Charles Tilly: história de um conceito. Sociologia \& Antropologia, v. 2, n. 3, p.21-41, 2012.

AVRITZER, L; Sociedade Civil e Estado no Brasil: da autonomia à interdependência política. Opinião Pública, v. 18, n. 2, p. 383-398, 2012. 
AVRITZER, L; Instituições participativas e desenho institucional: algumas considerações sobre a variação da participação no Brasil democrático. Opinião Pública, v. 14, n. 1, p. 43-64, 2008.

CARLOS, E. 2011. Movimentos sociais: revisitando participação e institucionalização. Lua Nova, v. 48. n. 84, p. 353-364, 2011.

DAGNINO, E.; OLVERA, A.; PANFICHI, A. Para uma outra leitura da disputa pela construção democrática na América Latina. In: DAGNINO, E. OLVERA, A.; PANFICHI, A (orgs.). A disputa pela construção democrática na América Latina. São Paulo: Paz e Terra, 2006. p. 13-91.

DOWBOR, M. A arte da institucionalização: estratégias de mobilização dos sanitaristas (1974-2006). Tese (doutorado), Universidade de São Paulo, Faculdade de Filosofia, Letras e Ciências Humanas, São Paulo, 2012.

DELLA PORTA, D.; DIANI, M. Social movements: an introduction. Oxford: Blackwell. 2006.

DIANI, M. The concept of social movement. The Sociological Review, v. 40, n. 1, p. 1-25, 1992.

GIUGNI, M.; PASSY, F. Contentious politics in complex societies: new social movements between conflict and cooperation. In: GIUGNI, M.; McADAM, D.; TILLY, C. (orgs.). From contention to democracy. Lanham: Rowman \& Littlefield, 1998. p. 81-107.

LAVALLE, A. Sem pena nem glória: o debate da sociedade civil nos anos 1990. Novos Estudos, v. 66, n. 66, p. 91-110, 2003.

LINDBLOM, C. Mudling through 1: a ciência da decisão incremental. In: HEIDEMANN, F. G.; SALM, F. (orgs.). Políticas públicas e desenvolvimento: bases epistemológicas e modelos de análise. Brasília: UnB, 2009, p. 161-180.

LUCHMANN, L. Associações, participação e representação: combinações e tensões. Lua Nova, n. 84, p. 141-174, 2011. 
MARQUES, E.; RODRIGUES, L. O Programa Minha Casa Minha Vida na metrópole paulistana. Revista Brasileira de Estudos Urbanos e Regionais, v. 15, n. 2, p. 159-177, 2013.

MARQUES, E. Redes sociais e permeabilidade do Estado: instituições e atores políticos na produção da infra-estrutura urbana no Rio de Janeiro. Tese (doutorado), Unicamp, Instituto de Filosofia e Ciências Humanas, Campinas, 1998.

MARQUES, E. Redes sociais e instituições na construção do Estado e sua permeabilidade. RBCS v. 14, n. 41, p. 45-67, 1999.

MARQUES, E. Redes sociais, Instituições e Atores Políticos no governo da cidade de São Paulo. São Paulo: Ed. Annablume. 2003.

MARQUES, E. De volta aos capitais para melhor entender as políticas urbanas. Novos Estudos, v. 35, n. 105. pg.15-33. 2016.

MARQUES, E. Em busca de um objeto esquecido: A política e as políticas do urbano no Brasil. RBCS v. 32, n. 95, p. 1-18, 2017.

McADAM, D. Conceptual origins, current problems, future directions. In: McADAM, D; McCARTHY, J.; ZALD, N. (orgs.). Comparative Perspectives on Social Movements: Political Opportunities, Mobilizing Structure, and Cultural Framings. Cambridge: Cambridge University Press, 2006, p. 23-40.

MELUCCI, A. The symbolic challenge of contemporary movements. Social Research, vol. 52, n. 4, p. 789-816, 1985.

MENEZES, D. Capacidade deliberativa e articulação política dos conselhos gestores: um estudo sobre o Conselho Estadual das cidades da Bahia. Dissertação (mestrado), Universidade Federal da Bahia, Faculdade de Filosofia e Ciências Humanas, 2015.

MENEZES, D. Conselhos Gestores e Políticas Públicas: o Conselho Estadual das Cidades da Bahia e a elaboração da Política Estadual de Resíduos Sólidos. In: VICTÓRIA, E.; UZEDA, D. (orgs). Democracia na América Latina. No prelo. 
MEYER, D.; TARROW, S. A Movement Society: Contentious Politics for a New Century. In:MEYER, D.; TARROW, S. (orgs.) The social movement society: contentions politics for a new century. Lanham, MA: Rowman\& Littlefield, 1998, p. 1-28.

MIGUEL, L. F. Mecanismos de exclusão política e os limites da democracia liberal: uma conversa com Poulantzas, Offe e Bourdieu. Novos Estudos, v. 33,n. 98, p. 145-161, 2014.

MUNCK, G. Formação de atores, coordenação social e estratégia política: problemas conceituais do estudo dos movimentos sociais. Dados, v. 40, n. 1, p. 105-125, 1997.

POULANTZAS, N. O Estado, o poder e o socialismo. São Paulo: Paz e Terra, 2000.

SERAFIM, L. Participação no Governo Lula: as pautas da reforma urbana no Ministério das Cidades (2003-2010). Tese (doutorado), UNICAMP, Instituto de Filosofia e Ciências Humanas, 2013.

SILVA, M.; OLIVEIRA, G. A face oculta(da) dos movimentos sociais: trânsito institucional e intersecção Estado-Movimento uma análise do movimento de Economia Solidária no Rio Grande do Sul. Sociologias, v. 13, n. 28, p. 86-124, 2011.

TATAGIBA, L. A questão dos atores, seus repertórios de ação e implicações para o processo participativo. In: PIRES, R. (org). Efetividade das instituições participativas no Brasil: estratégias de avaliação. Brasília: Ipea, 2011.

TATAGIBA, L. Relação entre movimentos sociais e instituições políticas na cidade de São Paulo: o caso do movimento de moradia. In: KOWARICK, L.; MARQUES, E. (orgs.). São Paulo: novos percursos e atores. São Paulo: Editora 34, 2011.

TATABIGA, L. BLIKSTAD, K. Como se fosse uma eleição para vereador: dinâmicas participativas e disputas partidárias na cidade de São Paulo. Lua Nova, n. 84, p. 175-217, 2011. 
TATAGIBA, L.; PATERNIANI, S.; TRINDADE, T. Ocupar, reivindicar, participar: sobre o repertório de ação do movimento de moradia de São Paulo. Opinião Pública, v. 18, n. 2, p. 399-426, 2012.

TATAGIBA, L.; TEIXEIRA, A. Efeitos combinados dos movimentos de moradia sobre os programas habitacionais autogestionários. Revista Sociologia e Política, v. 24, n. 58, p. 85-102, 2016.

TARROW, S. Poder em Movimento: movimentos sociais e confronto político. Petrópolis: Ed. Vozes, 2009.

TILLY, C. Popular Contention in Great Britain 1758-1834. Colorado: Paradigm Publisher, 2005.

TILLY, C. Movimentos Sociais como política. Revista Brasileira de Ciência Política, n. 3, p. 133-160, 2010.

TRINDADE, T. Protesto e democracia: ocupações urbanas e luta pelo direito à cidade. Jundiaí: Paco, 2017.

TRINDADE, T. BUGIATO, C. Contribuições teóricas do neomarxismo para o debate sobre a interação entre movimentos sociais e o Estado. In: Anais do III Encontro Internacional Participação, Democracia e Políticas Públicas, UFES, Vitória, 2017. 